\title{
Improvement of the durability of concrete with recycled aggregates in chloride exposed environment
}

\author{
Vázquez, E. ${ }^{1 *}$; Barra, M. ${ }^{1}$; Aponte, D. ${ }^{1}$; Jiménez, C. ${ }^{1}$; Valls, S. ${ }^{1}$ \\ ${ }^{1}$ Polytechnic University of Catalonia, Spain \\ "enric.vazquez@upc.edu,marilda.barra@upc.edu,diego.fernando.aponte@upc.edu, \\ cristian.jimenez@estudiant.upc.edu, susanna.valls@upc.edu
}

\begin{abstract}
Recycled aggregates concrete (RAC) becomes an important participant in recycled materials, although there are still questionable issues about some of its properties. Durability of RAC and its relationship with recycled concrete aggregate (RCA) is often discussed, especially in relation with chloride penetration and diffusion properties. An extensive experimental campaign was performed in order to evaluate the effect of RCA content in the retention and diffusion of chlorides in RAC. The influence of composition and mix design of the concrete was first studied using only a $20 \%$ replacement of natural aggregate by recycled aggregate. The $20 \%$ replacement was chosen in order to comply with Spanish recommendations for structural concrete. The $20 \%$ replacement was chosen in order to comply with Spanish recommendations for structural concrete. In the second part of the study concrete mixes ranging from 0.45 to $0.65 \mathrm{w} / \mathrm{c}$ ratios, with $0 \%, 20 \%, 50 \%$ and $100 \%$ coarse aggregates replacement were tested. Cement pastes, recycled aggregates and concretes were submitted to saline attack and the total chloride contents were determined. Chloride penetration profiles were determined by means of the NT BUILD 443 specifications. XRD and SEM aided the chlorides binding determination. A chlorides retention phenomenon is detected by the average diffusion coefficient decrease in RAC, thus compensating the RCA higher permeability. According to chloride binding and diffusion results, high RCA content lead to an improvement of durability in RAC with sufficiently low w/c ratio, in terms of chlorides attack.
\end{abstract}

Keywords. Durability, Chlorides Binding, Chlorides Diffusion, Recycled Aggregate Concrete, Recycled Concrete Aggregate.

\section{INTRODUCTION}

The construction materials are the most consumed from the engineering materials and the production of concrete exceeds that of all other construction materials together. Aggregate is the dominant material from a quantity point of view. The replacement of natural aggregate (NA) by RCA can contribute to the sustainability and to the conservation of natural resources. But because durability and sustainability are related, the use of RCA in structural 
concrete can reduce environmental impacts only depending on the application of the concrete. Comparing concrete with NA to a concrete with replacing of $>4 \mathrm{~mm}$ NA by RCA, some aspects of the durability conditioned by the environment must be addressed.

In environments with chlorides, the penetration of this ion can cause the corrosion of the rebar, and the diffusion of free chlorides into concrete can be very dangerous. As it is well known, the new cement paste and the old paste in recycled concrete can retain and bind chlorides. The presence sulphates can obstruct the chloride binding as they are strongly bound (Justnes, 1998). So RCA can contribute to chlorides binding, but the stability of this retention is very important. RCA must be as free as possible of chlorides and sulphates so the diffusion and degree of chloride binding will depend from other parameters like the composition and mix design of the concrete $(\mathrm{A})$; the coefficient will depend on the properties and relative quantity of new cement paste and RCA (B).

Some authors are pessimistic about the use of recycled structural concrete in environments with chlorides. A common simplification is to consider only the influence of the porosity of the RCA. Others obtain in their experiments good diffusion coefficients of the new concretes. Otsuki et al. (Otsuki, 2003) found that chloride penetration in high strength RAC was less than in an equivalent concrete with NA.

The objective of this study is to evaluate the effects of different relative proportions of RCA used, the contribution of properties of the new cement paste and the verification of the retention mechanisms of chlorides in order to facilitate a more extended use of RCA in structural concrete subjected to environments with chlorides, thus contributing to improve the sustainability of the constructions.

\section{MATERIALS AND METHODOLOGY}

The present investigation is divided in two phases, in which different aspects of chloride diffusion are shown: the influence of the composition and mix proportioning method of the concrete (A); the influence of the cement paste and RCA quantity (B); The Phase A used cement type CEM I 42.5 R and Phase B used CEM I52.5 R, coarse RCA, calcareous NA, both fines (FA) and coarse (CA), and superplastizicer (SP).

The chloride attack is performed through the immersion of the samples in a chloride-sodium solution over 35, 60 and 90 days. Such solution has a $165 \mathrm{~g} \mathrm{NaCl} / \mathrm{L}$ concentration, thus following the Nordtest Method NT BUILD 443 (NORDTEST, 1995). The determination of the soluble chlorides (free) is attained through UNE-EN 1744-1:2010 standard (Comité Técnico AEN/CTN 146 Áridos, 2010). The procedure for the total chlorides determination is shown in ASTM C 1152 (ASTM International, 1997).

\section{Phase A}

Six different concrete mixes were elaborated. Two designated BOLCON $0 \%$ using only NA in order to obtain a reference concrete, two designated BOLCON 20\% using a $20 \%$ replacement of NA by RCA, elaborated with common design practices, and two called BOLEMV 20\% using a 20\% replacement of NA but being designed with the novel method applied to BOLOMEY methodology. Two water/cement (w/c) ratios were used, 0.45 and 0.6 . The $20 \%$ replacement was chosen in order to comply with Spanish recommendations for structural concrete (Comisión Permanente del Hormigón, 2008). 
The adaptation of the novel method concluded in mix proportions with cement content reductions of about $8 \%$ for both 0.45 and 0.6 w/c ratios (Jiménez et al., 2012; Razaqpur et al., 2010). Table 1 shows the different mix proportions of the concretes.

Table 1. Phase A mixes proportioning summary

\begin{tabular}{|l|c|c|c|c|c|c|c|}
\hline \multicolumn{1}{|c|}{$I D$} & Water $(\mathrm{kg})$ & Cement $(\mathrm{kg})$ & W/c & $F A(\mathrm{~kg})$ & $C A(\mathrm{~kg})$ & $R C A(\mathrm{~kg})$ & $S P(\mathrm{~kg})$ \\
\hline BOLCON 0\% & 184 & 409 & 0.45 & 796 & 1085 & - & 1.5 \\
\hline BOLCON 20\% & 184 & 409 & 0.45 & 796 & 842 & 210 & 0.85 \\
\hline BOLEMV 20\% & 169 & 376 & 0.45 & 732 & 941 & 235 & 2.1 \\
\hline BOLCON 0\% & 184 & 307 & 0.60 & 958 & 1010 & - & - \\
\hline BOLCON 20\% & 184 & 307 & 0.60 & 914 & 819 & 205 & - \\
\hline BOLEMV 20\% & 171 & 286 & 0.60 & 892 & 876 & 219 & - \\
\hline
\end{tabular}

\section{Phase B}

The mix proportioning was based on a simple $0 \%, 20 \%, 50 \%$ and $100 \%$ volume replacement of NA by RCA. To evaluate the influence of the new cement matrix on the results, two w/c ratios were used: 0.45 and 0.55 . As shown in Table 2, a total of eight mix proportions were produced considering all variables mentioned previously.

Table 2. Phase B mixes proportioning summary

\begin{tabular}{|l|c|c|c|c|c|c|c|c|}
\hline \multicolumn{1}{|c|}{$I D$} & Water $(\mathrm{kg})$ & Cement $(\mathrm{kg})$ & W/C & $F A(\mathrm{~kg})$ & $C A(\mathrm{~kg})$ & $M A(\mathrm{~kg})$ & $R C A(\mathrm{~kg})$ & $S P(\mathrm{~kg})$ \\
\hline $\mathrm{H} 0-0.45$ & 173 & 385 & 0.45 & 814 & 871 & 168 & - & 3.85 \\
\hline $\mathrm{H} 20-0.45$ & 173 & 385 & 0.45 & 698 & 748 & 144 & 223 & 3.85 \\
\hline $\mathrm{H} 50-0.45$ & 173 & 385 & 0.45 & 742 & 432 & 83 & 515 & 3.85 \\
\hline $\mathrm{H} 100-0.45$ & 173 & 385 & 0.45 & 746 & - & - & 963 & 3.85 \\
\hline $\mathrm{H} 0-0.55$ & 179 & 325 & 0.55 & 875 & 755 & 254 & - & 3.25 \\
\hline $\mathrm{H} 20-0.55$ & 179 & 325 & 0.55 & 799 & 628 & 211 & 210 & 3.25 \\
\hline $\mathrm{H} 50-0.55$ & 179 & 325 & 0.55 & 831 & 367 & 123 & 491 & 3.25 \\
\hline $\mathrm{H} 100-0.55$ & 179 & 325 & 0.55 & 825 & - & - & 923 & 3.25 \\
\hline
\end{tabular}

The RCA was used in saturated surface-dry condition in phases A and B of the present investigation. The amount of water needed to achieve this condition was added and the aggregates were stored in hermetic drums 24 hours prior to mixing to avoid evaporation. Concrete specimens for the mechanical tests were cast in moulds with $150 \mathrm{~mm}$ of diameter and $300 \mathrm{~mm}$ of height, while the ones for durability tests were cast in mould with $100 \mathrm{~mm}$ of diameter and $200 \mathrm{~mm}$ of height. Manual compacting of the mixes was performed. The moulds were covered during the first 24 hours in order to minimize water evaporation. After that, the specimens were placed into a humidity and temperature controlled chamber $\left(20^{\circ} \mathrm{C}\right.$ and $97 \pm 2 \% \mathrm{RH}$ ) until testing.

\section{RESULTS AND DISCUSSION}

\section{Phase A}

Figure 1 shows the results for one of the mechanical tests of the elaborated concretes. 


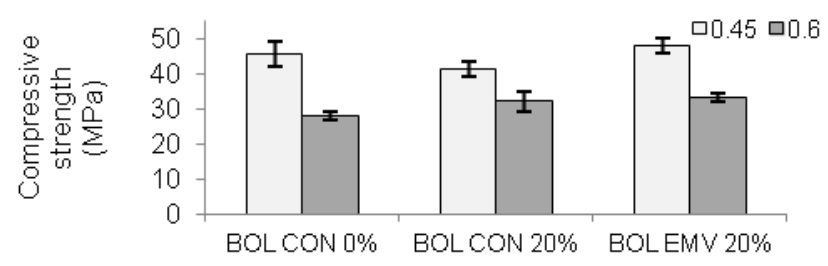

Figure 1. Phase A mixes compressive strengths

Even though there seems to be differences in the compression tests, after a statistical analysis there were found no significant differences. The $20 \%$ aggregates replacement did not implied major changes on this property, but an important outcome is attained due to the cement content reduction achieved for the BOLEMV mixes.

The experimental campaign concerning durability consisted on several tests, being the one related with a chloride environment the prescribed by NORDTEST in the NT BUILD 443 standard (NORDTEST, 1995).

The chloride profiles were obtained by grinding the samples at different depths in order to obtain concrete powder, which was then submitted to the chloride analysis by titration. After this, a non-linear regression analysis by means of the least squares fit method is performed in order to obtain the chloride transport coefficient (D) and the chloride concentration at the surface (Cs). With the results of the regression analysis, the behavior of the different concrete mixes to the chloride environment was examined. The results of this test are shown bellow.

Table 3. Phase A mixes chlorides results

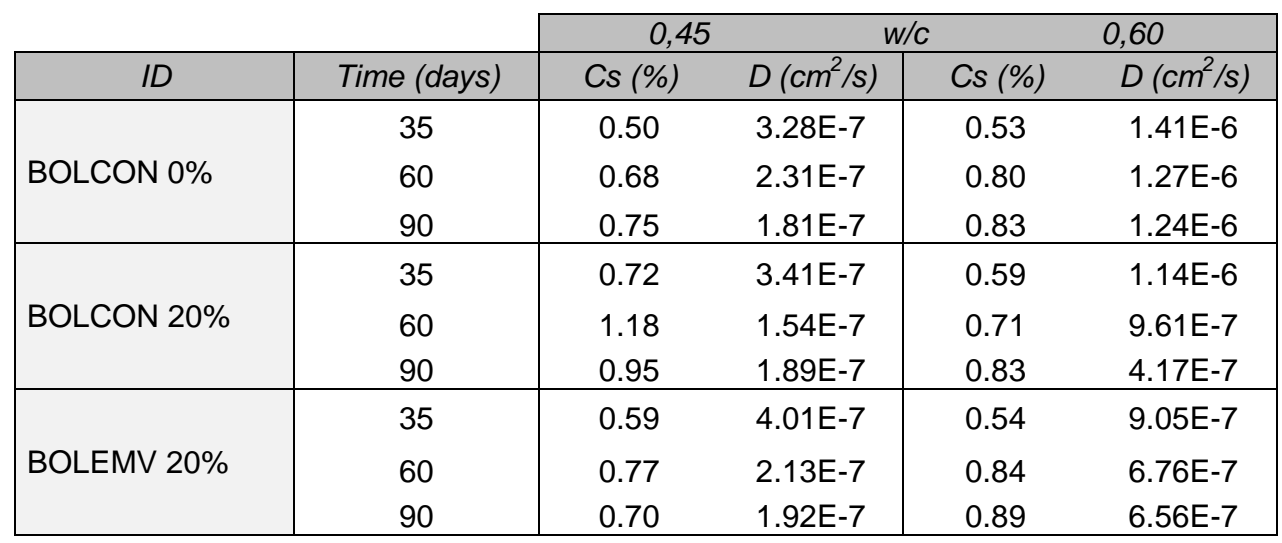

It can be seen that there may be a trend indicating that at higher age of testing, the chloride concentration on surface tends to increase and the chloride transport coefficient tends to decrease. These results indicate that the deposition of chlorides on the surface is higher over time, and that there may be a connection with the amount of chlorides penetrating the sample which decreases due to a blocking effect. Along time, chlorides are filling the concrete voids, thus obstructing the chloride penetration and so lowering the diffusion coefficient. 


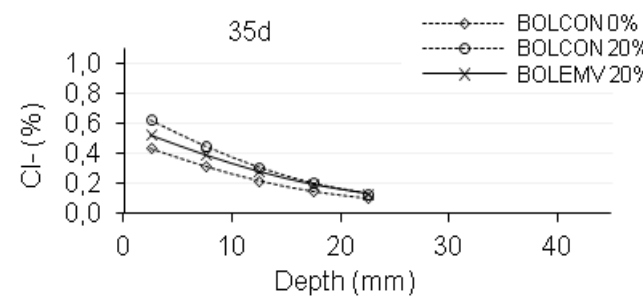

$\mathbf{2 a}$

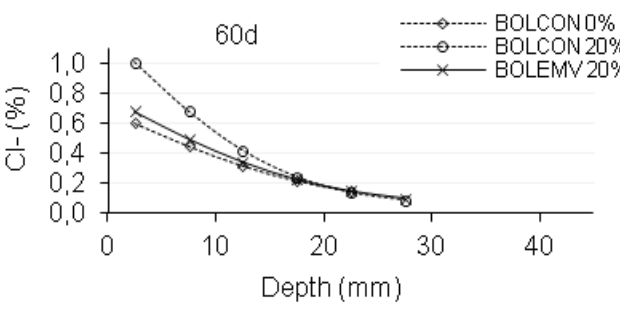

$2 \mathrm{~b}$
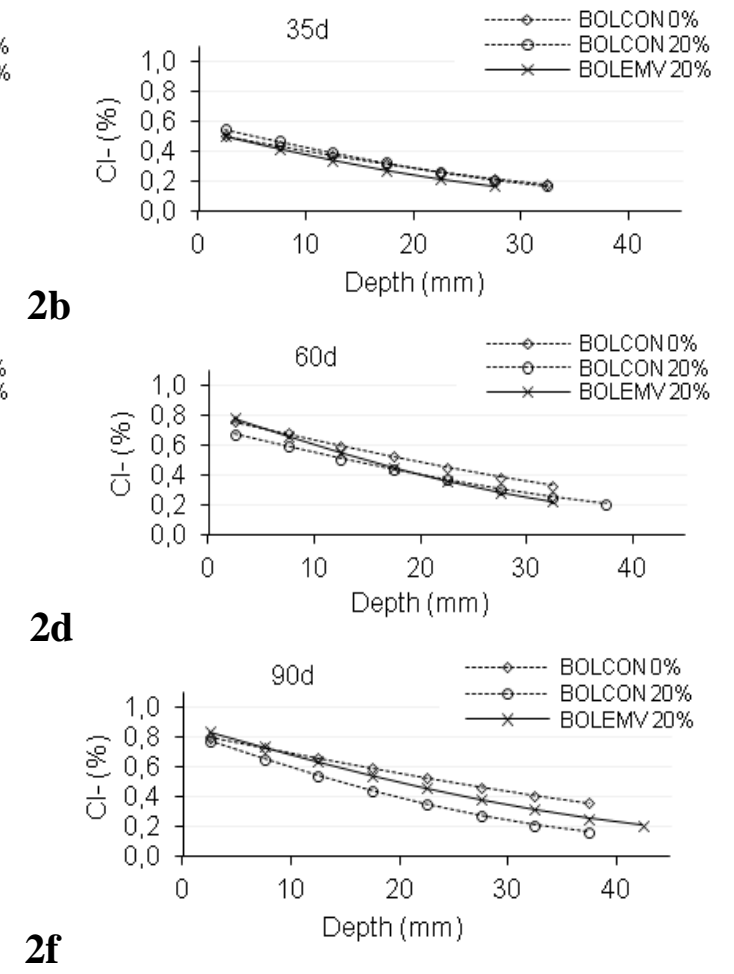

$\mathbf{2 e}$

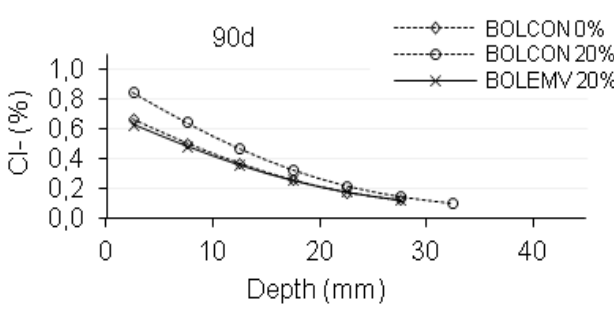

Figure 2. Phase A mixes chloride profiles: a) 35d, $0.45 \mathrm{w} / \mathrm{c}$ ratio; b) $35 \mathrm{~d}, 0.6 \mathrm{w} / \mathrm{c}$ ratio; c) 60d, $0.45 \mathrm{w} / \mathrm{c}$ ratio; d) $60 \mathrm{~d}, 0.6 \mathrm{w} / \mathrm{c}$ ratio; e) $90 \mathrm{~d}, 0.45 \mathrm{w} / \mathrm{c}$ ratio; f) $90 \mathrm{~d}$, $0.6 \mathrm{w} / \mathrm{c}$ ratio

From the graphs above, it can be notice that, in the case of the $0.45 \mathrm{w} / \mathrm{c}$ ratio, there is a clear trend for the chlorides behavior that indicates the different binding capacity of the concrete mixes, a behavior that has been commented by Nilsson et al. (Nilsson et al., 1996). BOLCON 20\% is the concrete achieving the higher binding capacity. This can be explained by the cement and RCA content of the mix. Both of them cause chlorides binding and, in this specific case, both achieve the maximum quantities compared to the other mix proportions. After, BOLEMV 20\% seems to be the mix binding more chlorides, a behavior that can be seen in the graphs at 35 and 60 days of exposure, with the exception of the 90 days graph which indicates an almost equal behavior than that of the BOLCON $0 \%$ mix. This seems to indicate that the $20 \%$ aggregate replacement has a major influence, over the $8 \%$ cement content difference, on the chloride binding capacity.

The $0.6 \mathrm{w} / \mathrm{c}$ ratio mixes do not show a clear tendency over all the obtained results, thus impeding an accurate conclusion over the chloride binding behavior. However, it can be said that for a given w/c ratio, the porous system of the concrete matrix may be the governing parameter over this property, thus leaving all of the other characteristics in a second plane. This assumption is of high importance, because it determines a limit for the w/c ratio of a concrete submitted to a certain chloride environment, since it may not be possible to avoid the deterioration of a given structure due to the chlorides attack. 


\section{Phase B}

The compressive strength of concretes of Phase B is shown in figure 3.

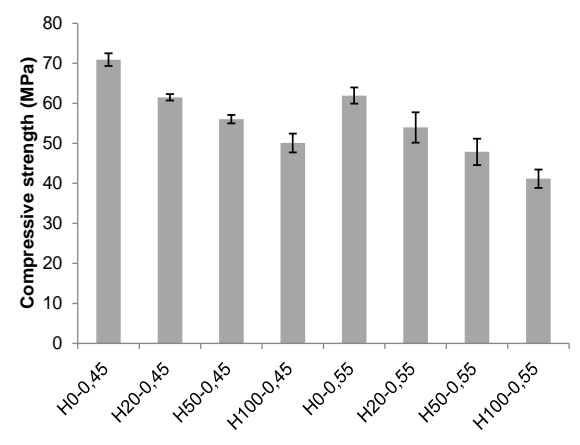

Figure 3. Phase B mixes compressive strengths

The compressive strength was calculated as the average of five tests. It is evident that the compressive strength decrease with the increment in the RCA content. There is an average compressive strength drop of $13 \%$ when using a $20 \%$ replacement, of $22 \%$ for a $50 \%$ replacement, and of $32 \%$ for a $100 \%$ replacement.

Compressive strength of the RAC is influenced by different aspects, such as the amount of free water, the amount of cement and the RCA characteristics. In general, the substitution of NA by RCA is expected to reduce the compressive strength and the elasticity modulus of the concrete. This may be due to the lower strength of the RCA or the characteristics of the interfacial transition zones between the old and new mortar which may lead to more defects in the concrete (Alaejos et al., 2006; de Brito \& Alves, 2010; Sim \& Park, 2011).

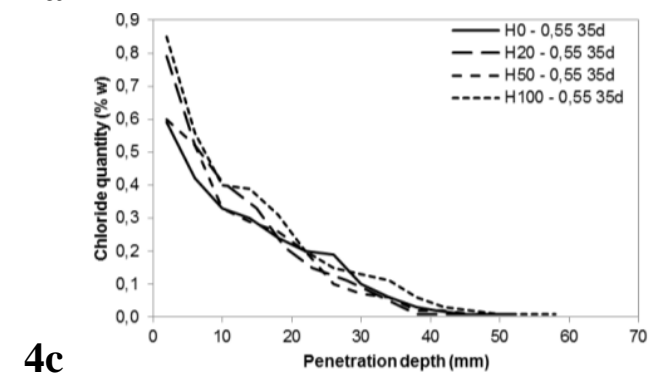

4b
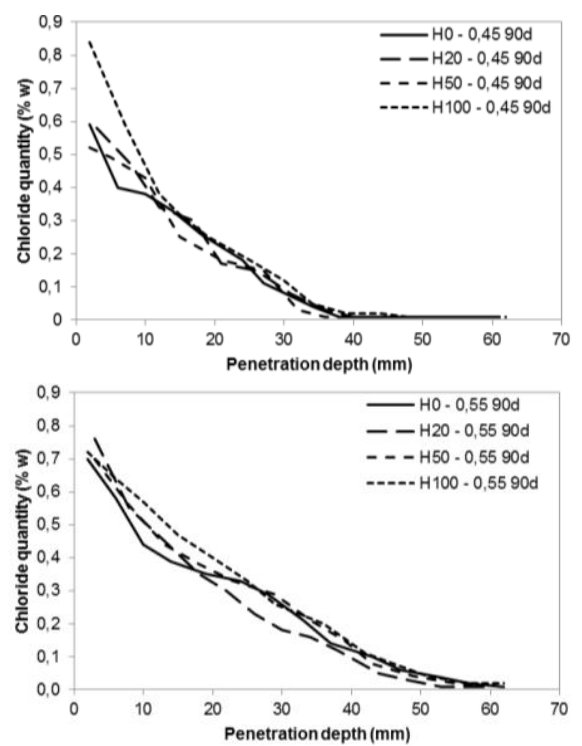

Figure 4. Phase B mixes chloride profiles: a) 35d, 0.45 w/c ratio; b) $90 \mathrm{~d}, 0.45$ w/c ratio; c) $35 \mathrm{~d}, 0.55 \mathrm{w} / \mathrm{c}$ ratio; d) $90 \mathrm{~d}, 0.55 \mathrm{w} / \mathrm{c}$ ratio 
Table 4. Chloride diffusion coefficient measured for different mixes

\begin{tabular}{|l|c|c|}
\hline \multicolumn{1}{|c|}{ Concrete ID } & 35 days $\left(\mathrm{cm}^{2} / \mathrm{s}\right)$ & 90 days $\left(\mathrm{cm}^{2} / \mathrm{s}\right)$ \\
\hline $\mathrm{H} 0-0.45$ & $5.02 \mathrm{E}-7$ & $3.01 \mathrm{E}-7$ \\
\hline $\mathrm{H} 20-0.45$ & $5.20 \mathrm{E}-7$ & $2.08 \mathrm{E}-7$ \\
\hline $\mathrm{H} 50-0.45$ & $2.71 \mathrm{E}-7$ & $3.11 \mathrm{E}-7$ \\
\hline $\mathrm{H} 100-0.45$ & $2.91 \mathrm{E}-7$ & $2.25 \mathrm{E}-7$ \\
\hline $\mathrm{H} 0-0.55$ & $7.41 \mathrm{E}-7$ & $5.41 \mathrm{E}-7$ \\
\hline $\mathrm{H} 20-0.55$ & $7.65 \mathrm{E}-7$ & $5.00 \mathrm{E}-7$ \\
\hline $\mathrm{H} 50-0.55$ & $6.60 \mathrm{E}-7$ & $6.18 \mathrm{E}-7$ \\
\hline $\mathrm{H} 100-0.55$ & $6.12 \mathrm{E}-7$ & $6.20 \mathrm{E}-7$ \\
\hline
\end{tabular}

The diffusion coefficient of mixes with the same w/c ratio and low RCA content $(0 \%$ and $20 \%)$ show very similar diffusion coefficients. The same is observed between mixes with high RCA content (50\% and 100\%). Furthermore, it is observed that the substitution of NA in a percentage superior to $20 \%$ produces a decrease of $18 \%$ and $80 \%$ on the average diffusion coefficient for mixes with w/c ratios equal to 0.55 and 0.45 , respectively.

Such results show a tendency that once more goes against what it was expected, due to the permeability of concrete. Indeed, if the diffusion process would be just affected by the permeability, the mixes with higher RCA content should present higher chloride diffusion coefficients since they tend to be more permeable. Therefore, it is clear that another phenomenon, acting in parallel to the simple diffusion of chlorides, is responsible for the results. This phenomenon is the chloride retention, which should be higher in the mixes with more RCA. Therefore, according to the estimation performed, the use of a high RCA content had a positive repercussion, leading to a less permeable concrete to chlorides.

As expected, it was also observed that the change on the w/c ratio from 0.45 to 0.55 produces an increase on the diffusion coefficient. Such increase is approximately of $47 \%$ in mixes with low RCA content ( $0 \%$ and $20 \%)$, and of $127 \%$ in mixes with high RCA content (50\% and 100\%), measured at 35 days. At 90 days the increase is $110 \%$ in mixes with low RCA content, and $137 \%$ in mixes with high RCA content. Consequently, the latter appear to be more sensible to variations in the $w / c$ ratio.

\section{CHLORIDE RETENTION MECHANISM IN RAC}

Chloride binding in concrete can be due to a chemical reaction between chlorides and hydrated cement aluminates or to physico-chemical adsorption in the CSH (Villagrán Zaccardi et al., 2008).

In the first case, the produced compounds are mainly the hydrated monochloro-aluminate, also called Friedel's salt, which formula is $\mathrm{C}_{3} \mathrm{~A} \cdot \mathrm{CaCl}_{2} \cdot 10 \mathrm{H}_{2} \mathrm{O}$, and the trichloro-aluminate $\mathrm{C}_{3} \mathrm{~A} .3 \mathrm{CaCl}_{2} \cdot 30 \mathrm{H}_{2} \mathrm{O}$, both coming from the reaction of $\mathrm{Cl}$ - ions with the tricalcium-aluminate $\mathrm{C}_{3} \mathrm{~A}$. In another hand, the tetracalcium-ferroaluminate $\left(\mathrm{C}_{4} \mathrm{AF}\right)$ is also susceptible of producing an analogue chlorated salt to the Friedel's salt, named calcium-chloroferrate $3 \mathrm{CaO} \cdot \mathrm{Fe}_{2} \mathrm{O}_{3} \cdot \mathrm{CaCl}_{2} \cdot 10 \mathrm{H}_{2} \mathrm{O}$. However, the $\mathrm{C}_{3} \mathrm{~A}$ reacts faster with the chlorides than the $\mathrm{C}_{4} \mathrm{AF}$ (Lannegrand et al., 2001). 
Chlorides, coming from an external medium, could be bound by the new cement paste of the $\mathrm{RAC}$ and the old mortar which is adhered to the RCA. This analysis is performed separately, in the cement paste and in the RCA.

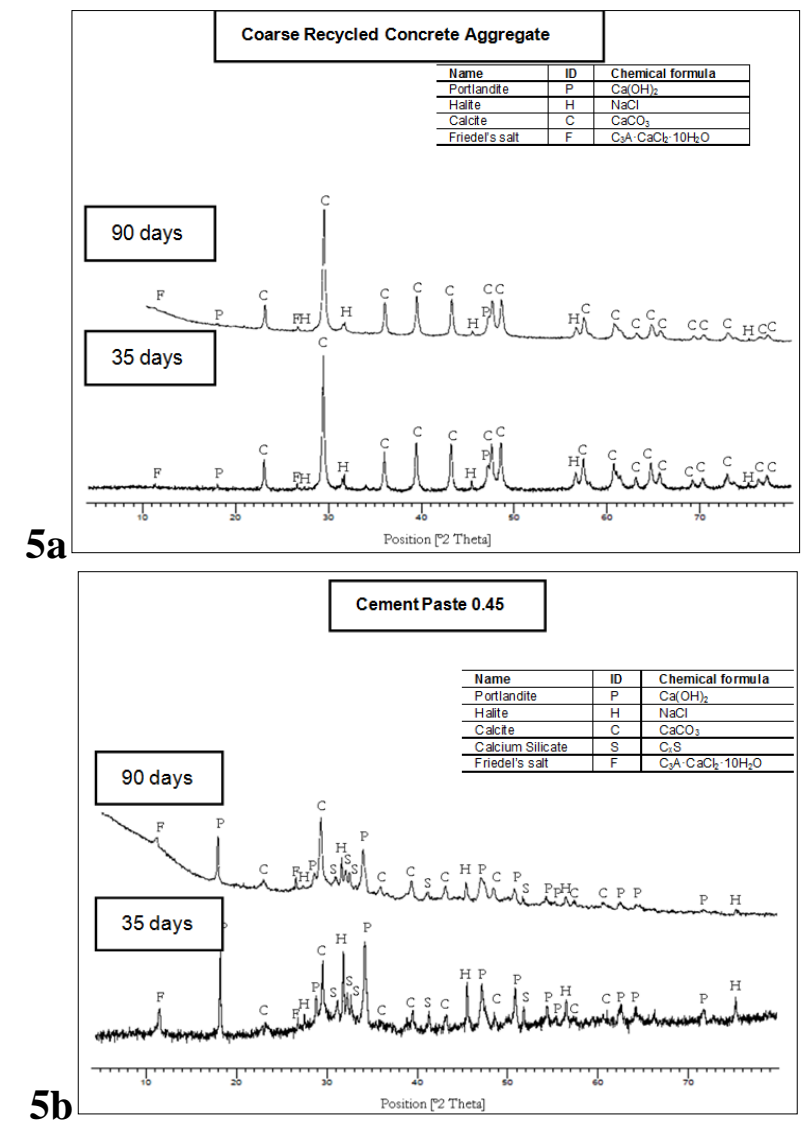

Figure 5. a) DRX of RCA exhibit at $\mathrm{NaCl}$ solution; b) DRX of cement paste exhibit at $\mathrm{NaCl}$ solution

Friedel's salt formation is detected in both cement pastes and RCA, but the latter ones with less intensity (Figure 5a, 5b).
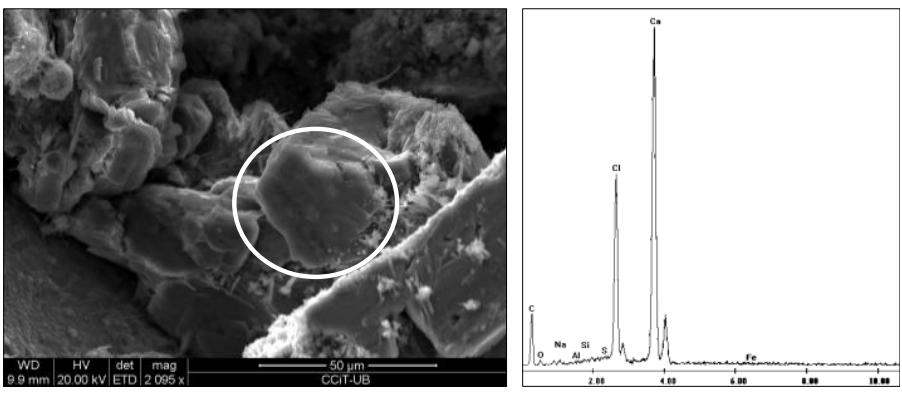

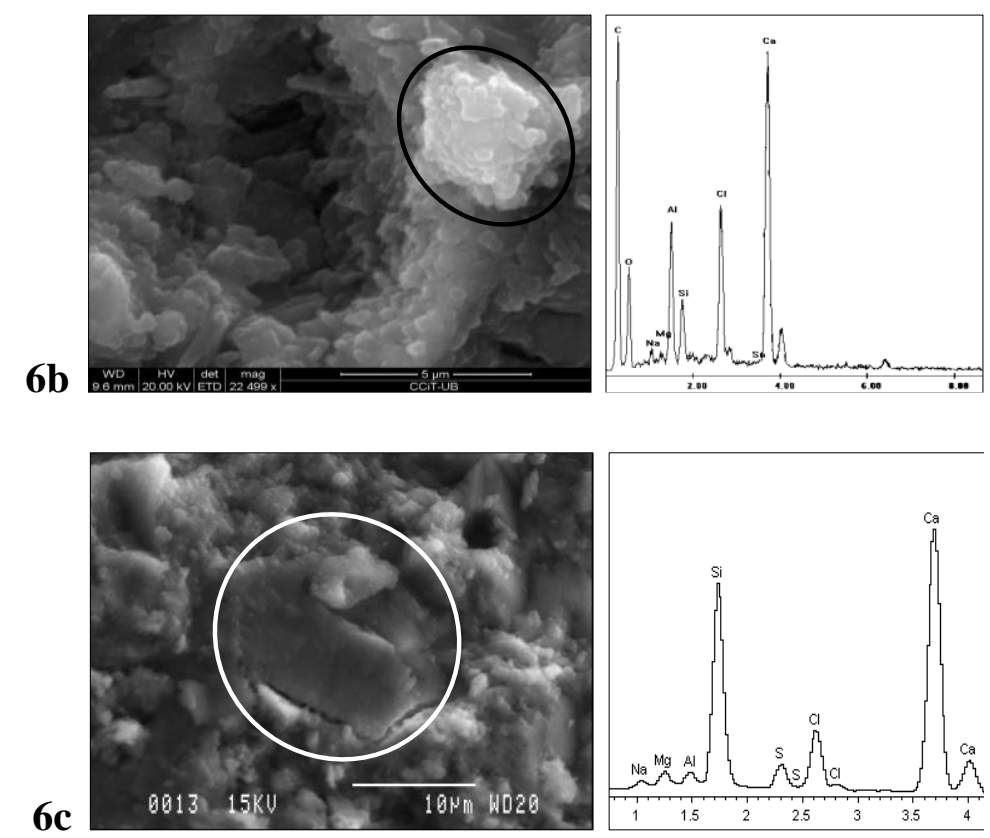

\section{Figure 6. a) SEM, calcium chloride in cement paste, b) SEM, Friedel's salt in cement paste, c) SEM, Chlorides binding in CSH gel}

In Figure 6b, a wide stacked plaques type zone is observed which, according to the spectrum, could be Friedel's salt. In effect, the higher peaks correspond to chlorine, aluminum and calcium. However, although silicon peak is lower, it is also visible. This could be due to the fact that Friedel's salt plaques are thin. Some elements in the surrounding areas are also detected in the spectrums, silicon in this case.

Finally, chlorides binding in concrete could be due to a physico-chemical adsorption in the $\mathrm{CSH}$. Figure $6 \mathrm{c}$ shows the chloride binding in a CSH plaque. In the spectrum, calcium, silicon and chlorine peaks can be seen.

\section{CONCLUSSIONS}

The experimental work has shown the possibility of used of recycled aggregate concrete in a safe and sustainable way.

The use of the novel method for RAC mix proportioning, ends in similar compressive strengths and chlorides attack performances to those of a NAC and a conventional RAC, with significant reductions on the cement contents of the mixes, thus representing an important improvement in terms of sustainability.

The chloride binding is a complex process and it is affected by many factors, such as quantity and type of cement, w/c ratio, age curing, etc. Furthermore, experimental evidence has been found of the effect of recycled aggregate in binding chlorides. 
The chloride binding is principally dominated by the C3A and C4AF, but the $\mathrm{CSH}$ gel has an important role thus, the use of recycled aggregate increases the binding of chloride as it provides an extra quantity of CSH gel that helps the chloride sorption. It has been also observed that the calcium hydroxide can combine with chlorides, forming calcium chloride, but significant quantities have not been observed.

\section{REFERENCES}

Alaejos, P. et al., 2006. Draft of Spanish standard for the use of recycled aggregate in the production of structural concrete. In Proceedings of the 6th International Symposium on Cement \& Concrete and CANMET/ACI International Symposium on Concrete Technology for Sustainable Development., 2006.

ASTM International, 1997. Standard Test Method for Acid-Soluble Chloride in Mortar and Concrete. Standard. ASTM International.

Comisión Permanente del Hormigón, 2008. Instrucción de Hormigón Estructural. EHE-08. Primera Edición ed. Madrid: Ministerio de Fomento.

Comité Técnico AEN/CTN 146 Áridos, 2010. Ensayos para determinar las propiedades químicas de los áridos. Parte 1: Análisis químico. Standard. Madrid: AENOR AENOR.

Comité técnico AEN/CTN 80 Cementos y cales, 2010. UNE 80213:2010. Métodos de ensayo de cementos. Determinación potenciométrica de cloruros. Standard. Madrid: AENOR AENOR.

de Brito, J. \& Alves, F., 2010. Concrete with recycled aggregates: the Portuguese experimental research. Materials and Structures, 43(1), pp.35-51.

Jiménez, C. et al., 2012. Equivalent Mortar Volume (EMV) method for proportioning recycled aggregate concrete: Validation under the Spanish context and its adaptation to Bolomey methodology for concrete proportioning. MATERIALES DE CONSTRUCCIÓN.

Justnes, H., 1998. A review of chloride binding in cementitious systems. Nordic Concrete Research, 21, pp.1-6.

Lannegrand, R., Ramos, G. \& Talero, R., 2001. Condition of knowledge about the Friedel's salt. MATERIALES DE CONSTRUCCIÓN, 51(262), pp.63-71.

Nilsson, L.-O. et al., 1996. ISSN/ISBN: 0909-4288 / 8774917366 HETEK, Chloride penetration into concrete, State-of-the-Art, Transport processes, corrosion initiation, test methods and prediction models. Danish Road Directorate.

NORDTEST, 1995. 0283-7153 NT BUILD 443:1995. Hardened Concrete: Accelerated Chloride Penetration. Standard. Espoo: NORDTEST.

Otsuki, N.M., 2003. Influence of recycled aggregate on interfacial transition zone, strength, chloride penetration and carbonation of concrete. Journal of Materials in Civil Engineering, 155, pp.443-51.

Otsuki, N., Nagataki, S. \& Nakashita, K., 1992. Evaluation of AgNO3 Solution Spray Method for Measurement of Chloride Penetration into Hardened Cementitious Matrix Materials. ACI Materials Journal, 89(6), pp.587-92.

Razaqpur, A.G. et al., 2010. How to produce high quality concrete mixes with recycled concrete aggregate. In J.Z. Xiao, Y. Zhang, M.S. Cheung \& R.P.K. Chu, eds. Construction Waste Recycling and Civil Engineering Sustainable Development - Proceedings of the ICWEM 2010. Shanghai: RILEM Publications S.A.R.L. pp.11-35.

Sim, J. \& Park, C., 2011. Compressive strength and resistance to chloride ion penetration and carbonation of recycled aggregate concrete with varying amount of fly ash and fine recycled aggregate. Waste Management, 31(11), pp.2352-60.

Villagrán Zaccardi, Y., Zega, C. \& Di Maio, Á., 2008. Chloride Penetration and Binding in Recycled Concrete. Journal of Materials in Civil Engineering, 20(6), pp.449-55. 